\title{
The 1,3-Dipolar Cycloaddition of Nitrile Oxide to Vinylacetic Acid: Computational Study of Transition States Selectivity, Solvent Effects, and Bicyclo Formation
}

\author{
Josene M. Toldo, *a Aloir A. Merlo ${ }^{b}$ and Paulo F. B. Gonçalves ${ }^{a}$ \\ ${ }^{a}$ Grupo de Química Teórica and ${ }^{b}$ Laboratório de Química Orgância e Materiais Inteligentes, \\ Instituto de Química, Universidade Federal do Rio Grande do Sul, Av. Bento Gonçalves, 9500, \\ 91501-970 Porto Alegre-RS, Brazil
}

\begin{abstract}
The 1,3-dipolar cycloaddition reaction is a powerful tool for the cycloaddition of nitrile oxides to olefins, and this reaction is of considerable interest to obtain isoxazolines. Density functional theory (DFT) was used to study the 1,3-dipolar cycloaddition reaction mechanism that initially occurs between benzonitrile oxide and vinylacetic acid to yield a bicyclo, from successive cycloadditions. PBE1PBE, B3LYP and CAM-B3LYP functionals were used together with 6-311+G(2d,p) basis set. $\operatorname{CCSD}(\mathrm{T}) / 6-311+\mathrm{G}(2 \mathrm{~d}, \mathrm{p})$ calculations were done to compare the DFT energy barriers. The solvent effects were included using polarizable continuum model (PCM), with three different solvents. In the first cycloaddition, only the 3,5-regioisomer is expected. In the gas phase, the $\beta$ face attack, that originates the trans-bicyclo, is slightly favored, but the cis-bicyclo is considerably more stable. However, the $\alpha$ face attack was favored with solvent effects. The PBE1PBE functional gives the closest activation energies and reaction energies to $\operatorname{CCSD}(\mathrm{T})$. The inclusion of solvent effects changes the preferential rotamer in each cycloaddition.
\end{abstract}

Keywords: DFT benchmark, 1,3-dipolar cycloaddition, benzonitrile oxide, $\operatorname{CCSD}(\mathrm{T})$.

\section{Introduction}

The 1,3-dipolar cycloaddition (13DC) is a powerful tool for the synthesis of a range of five-membered ring heterocycles. ${ }^{1}$ These reactions are stereospecific, regiospecific and diasteroselective ${ }^{2,3}$ and have been applied to organic synthesis, ${ }^{4}$ materials chemistry, ${ }^{5,6}$ drug discovery, ${ }^{7,8}$ and, most recently, have also been employed to modify carbon materials, such as fullerene, ${ }^{9}$ carbon nanotubes,${ }^{10}$ and graphene. ${ }^{11,12}$ The cycloaddition of nitrile oxides to olefins, in particular, has considerable interest for obtaining isoxazoline rings, ${ }^{13}$ substrates of many products with biological activity ${ }^{14-16}$ and organic molecules with technological interest, such as liquid crystal materials ${ }^{17}$ and organic semiconductors. ${ }^{18}$

From the pioneering work of Huisgen, ${ }^{19,20}$ who postulated the concerted reaction mechanism of cycloaddition reactions, this kind of reaction has been widely studied, both theoretically and experimentally. ${ }^{21-30}$ The control of regioselectivity of 13DC has been explained by frontier molecular orbital (FMO) analysis. ${ }^{2,3}$ In this treatment, the nucleophilicity and electrophilicity of the species are based

*e-mail: josene.toldo@ufrgs.br on HOMO and LUMO energies and orbital coefficients. ${ }^{3,31}$ Using the FMO and the Sustmann classification, ${ }^{32}$ it is possible to explain one of the most common characteristics of 13DC reactions which involve nitrile oxides and alkenes with electron-rich $\pi$ systems and electron-deficient $\pi$ systems. When electron-donating groups are bonded to alkene, the reaction provides only 5-regioisomers. However, if the alkene has electron-withdrawing groups attached, it usually yields a mixture of 4- and 5-regioisomers. ${ }^{33-35}$

Density functional theory (DFT) methods are most frequently employed for quantum mechanical calculations of 13DC because of the balance between accuracy and efficiency. A large number of studies involving the theoretical study of 13DC reactions have been published recently, and DFT has emerged as the theoretical choice in many cases. ${ }^{36,37}$ Among these functionals, B3LYP is the most popular in the quantum investigations of 13DC and has been shown to provide reasonable geometries and energies. ${ }^{38-40}$ In general, B3LYP describes 13DC reaction mechanisms in a satisfactory way, compared to more high-level calculations. ${ }^{34,35}$

In previous theoretical reports, Ess and Houk ${ }^{37}$ systematically investigated the reactivity of diazonium, nitrilium, and azomethine betaine classes of 1,3-dipoles 
with ethylene and acetylene. The performance of DFT and MP2 methods and basis sets for the prediction of activation barriers and reaction energies are obtained and compared with the highly accurate CBS-QB3 method. The B3LYP/6-31G(d) method performed best for reaction enthalpies, with a mean absolute deviation (MAD) value of $2.4 \mathrm{kcal} \mathrm{mol}^{-1}$, while the activation enthalpies had a MAD value of $1.5 \mathrm{kcal} \mathrm{mol}^{-1}$. Subsequently, the 13DC reactions of 24 1,3-dipoles with ethylene and acetylene were used to benchmark some DFT and ab initio methods to find an economical and accurate method that could be applied to large systems. ${ }^{41}$ Compared to the high-accuracy G3B3 method, employed as the reference, the CBS-QB3 and single and double excitation coupled cluster theory including an estimate of connected triple excitations by a perturbational treatment $(\mathrm{CCSD}(\mathrm{T})) / \mathrm{maug}-\mathrm{ccpV}(\mathrm{T}+\mathrm{d}) \mathrm{Z} / / \mathrm{B} 3 \mathrm{LYP}$ methods provided similar results for both activation and reaction enthalpies (MAD $\left.<1.5 \mathrm{kcal} \mathrm{mol}^{-1}\right)$. The B3LYP functional also provided good results for most of the 1,3-dipoles with a MAD of $1.9 \mathrm{kcal} \mathrm{mol}^{-1}$. However, for the Diels-Alder reaction, B3LYP sometimes produces significantly different transition state geometries, because of their tendency of very asynchronous transition states (TS). ${ }^{42}$

Other functionals, such as PBE1PBE and CAM-B3LYP, are not generally used in the study of cycloaddition reactions. The first one is most commonly employed in materials science and in the solid state, ${ }^{43}$ but can produce good results for Diels-Alder reactions. ${ }^{42}$ This functional uses $25 \%$ exchange and $75 \%$ correlation weighting and does not include empirical parameters. ${ }^{44}$ The CAM-B3LYP functional combines the hybrid qualities of B3LYP and the long-range correction not described correctly by B3LYP. ${ }^{45}$ The main difference between the B3LYP and CAM-B3LYP functionals is the amount of exact Hartree-Fock (HF) exchange included. The B3LYP functional includes a fixed amount of $20 \% \mathrm{HF}$ exchange, whereas amount of HF exchange varies from 19 to $85 \%$ in the CAM-B3LYP functional. The non-Coulomb part of the exchange functionals dies off too rapidly and becomes very inaccurate at large distances, making them unsuitable for modeling some processes. In particular, an increased amount of exact HF exchange has been shown to be advantageous when treating anions and Rydberg states, since the associated diffuse orbitals will be described by the pure B88 exchange functional.

The solvent effects in the 13DC of benzonitrile oxide (BNO) and their derivatives are remarkably small. ${ }^{46}$ Engberts and co-workers ${ }^{47}$ conducted a kinetic experimental study involving 13DC reactions between BNO and several electron-rich (ER) dipolarophiles and electron-deficient (ED) dipolarophiles in various organic solvents and water. As a result, they found that reactions involving ER dipolarophiles took place 3-10 times faster in water than in most organic solvents. However, the reactions involving ED dipolarophiles were slightly slower in water. Subsequently, Rispens and Engberts ${ }^{48}$ studied the kinetics of the BNO reactions with a range of $N$-substituted maleimides and cyclopentene in water and in other organic solvents. They demonstrated the importance of solvent polarity and hydrogen bonding (HB) in the kinetic control of these reactions.

The solvent effect in 13DC reactions has also been studied theoretically by other authors. For instance, Benchouk et al. ${ }^{36}$ have applied DFT and the polarizable continuum model (PCM) to explain the experimental results found by Rispens and Engberts. ${ }^{48}$ They found that the reaction was slightly slowed by polar solvents since the transition state of 13DC reactions have a smaller polar character than reactants. However, they found that protic solvents have a usual effect in terms of reaction rate. Surprisingly, reactions in water differ strongly from those in other solvents. They were slightly accelerated because the coordination of a water molecule to BNO puts in evidence the importance of hydrogen bonding in the modest acceleration of the $13 \mathrm{DC}$ reaction experimentally observed. The regioselectivity and solvent effects of the 13DC reactions of BNO with ED alkynes and alkenes has been studied by Hu and Houk, ${ }^{35}$ using B3LYP/6-31G(d) and PCM (water and carbon tetrachloride). They found that the reactions between fulminic acid and mesitonitrile oxide with ED methyl propiolate and cyanoacetylene presented poor regioselectivity, yielding a mixture of two regioisomers. However, the solvent effects could change the regioselectivity of these reactions due to the large polar character of the more unfavorable transition states. Therefore, 3,5-regioisomer formation was accelerated by increasing the solvent polarity. Domingo et al..$^{49}$ studied the influence of the solvent in the reaction between ER BNO and 3-metileneftalamine using PCM. They evaluated the possibility of a concerted and diradical mechanism and concluded that, in the former case, a highly polar transition state was expected, while in the two step mechanism there was no significant charge and therefore the presence of polar solvents should not affect the reaction.

In a previous work, we reported the synthesis and mesomorphic behavior of new liquid crystals from [3+2] 1,3-dipolar cycloaddition of arylnitrile oxides with vinylacetic acid. ${ }^{17}$ To better understand this reaction, the mechanism of the 13DC between vinylacetic acid (1) and benzonitrile oxide (2) (Scheme 1) was studied using different DFT functionals and post Hartree-Fock calculations. Considering the large use of B3LYP functional to describe cycloaddition reactions and taking into account 


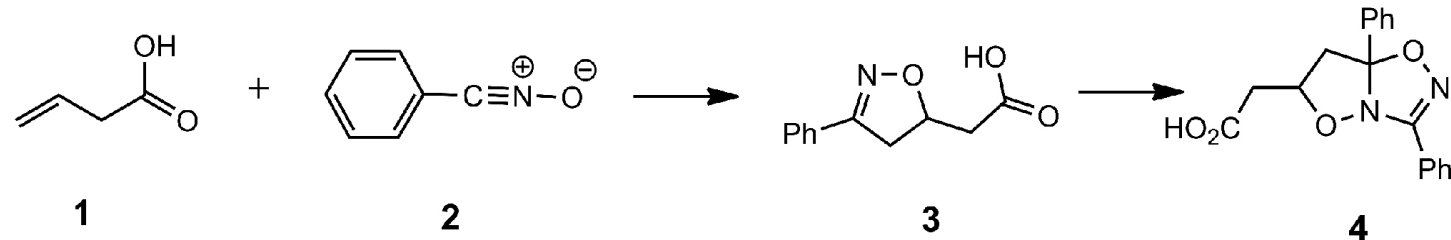

Scheme 1. [3 + 2] 1,3-Dipolar cycloaddition reaction between vinylacetic acid (1) and nitrile oxide (2) yields the cycloadduct (3) and afterwards the 2:1 cycloadduct (4).

the great popularity of the PBE1PBE and CAM-B3LYP functionals, added to the lack of publications using these functionals to describe this type of reaction, we decided to compare the results obtained between them. In addition, $\operatorname{CCSD}(\mathrm{T})$ calculations were done to compare the accuracy of DFT in predicting activation energies and reaction energies. The solvent effects were also evaluated by using conductor-like polarizable continuum model (CPCM) and PCM formalism considering tetrahydrofuran (THF), acetonitrile (ACN) and formamide (FORM) as solvents.

\section{Methodology}

DFT calculations were carried out using B3LYP, ${ }^{50}$ PBE1PBE ${ }^{44}$ and CAM-B3LYP ${ }^{45}$ hybrid functionals together with the $6-311+\mathrm{G}(2 \mathrm{~d}, \mathrm{p})$ basis set The solvent effects were included with $\mathrm{CPCM}^{51,52}$ and $\mathrm{PCM}^{53}$ formalisms together with three solvents with a different dielectric constant, i.e., THF ( $\varepsilon=7.43)$, ACN $(\varepsilon=35.69)$ and FORM ( $\varepsilon=108.94)$, with the aim of evaluating the possible changes in the reaction energetic profile with the increase of dielectric constant of the environment. The solvent effects were considered at the same level of theory (DFT level) by performing optimization energy calculations and frequency calculations to characterize the stationary points. The intrinsic reaction coordinate (IRC) ${ }^{54,55}$ paths were traced to check the energy profiles connecting each TS to the two associated minima of the proposed mechanism, in the gas phase. The electronic structures of the stationary points were analyzed using the natural bond orbital method (NBO 3.1 $)^{56}$ present in the Gaussian 09 program package. All calculations were performed with the Gaussian 09 suite of programs..$^{57}$ The basis set superposition error (BSSE) was evaluated at the transition structures in the gas phase, using B3LYP/6-311+G(2d,p) but not showing a significant effect. The zero point energy corrections (ZPE) were considered in all calculations. ${ }^{58}$ In order to evaluate the results obtained with DFT methods, CCSD(T)/6-311+G(2d,p) single point calculations were performed using B3LYP/6-311+G(2d,p) geometries in the first cycloaddition together with CPCM and THF as solvent.

Due to the similarity between the results obtained with the two models of solvation, the second cycloaddition calculations were performed using only the CPCM model. The B3LYP calculations were performed in the gas phase and including THF, ACN and FORM as solvents. Due to the computational cost, calculations using PBE1PBE and CAM-B3LYP were performed only in the gas phase using the CPCM model and THF as solvent, in the second cycloaddition.

The informations about the synthesis, structural characterization and mesomorphic behavior of the liquid crystal bisadduct compounds obtained from the 13DC reaction studied can be found in reference 17.

\section{Results and Discussion}

\section{Stereoselectivities of transition structures}

The selectivity in cycloaddition reactions can be explained using the conformational analysis of transition structures. ${ }^{59-63}$ Transition structures prefer a staggered orientation around the forming bonds. For nitrile oxide cycloadditions, this leads to three possible positions for a substituent: inside, outside, or anti relative to the forming bonds of the cycloaddition transition structure (Scheme 2)..$^{59}$

Transition structures involving $\alpha$-substituted alkenes should be carefully analyzed. If the alkene has an $\alpha$-chiral carbon, there is the possibility of attack by any pro-chiral face of the olefin (to give the syn and anti cycloadducts). ${ }^{4,64}$ Therefore, considering the three staggered rotamers, for each regioisomer it is possible to find six structures for the transition state, three for each face. The stereoselectivity in the cycloadditions of nitrile oxides with chiral allylic ethers ${ }^{65,66}$ and homoallylic alcohols ${ }^{59}$ is explained by Houk and co-workers. While groups with $\alpha$-alkoxy substituents prefer to guide the alkoxy groups in the inside position (the "inside alkoxy effect"), 4,66 hydroxyl groups have a preference for the outside position, in order to enable hydrogen bonding with the incoming nitrile oxide oxygen. However, in both cases, large alkyl groups prefer the anti position,,$^{59,66,67}$ but steric interactions from $Z$-alkenes have been found to alter the conformational preference of electronegative substituents. ${ }^{61}$

Considering these effects, seven transition structures were calculated for the first cycloaddition (TS1) (Figure S1). 


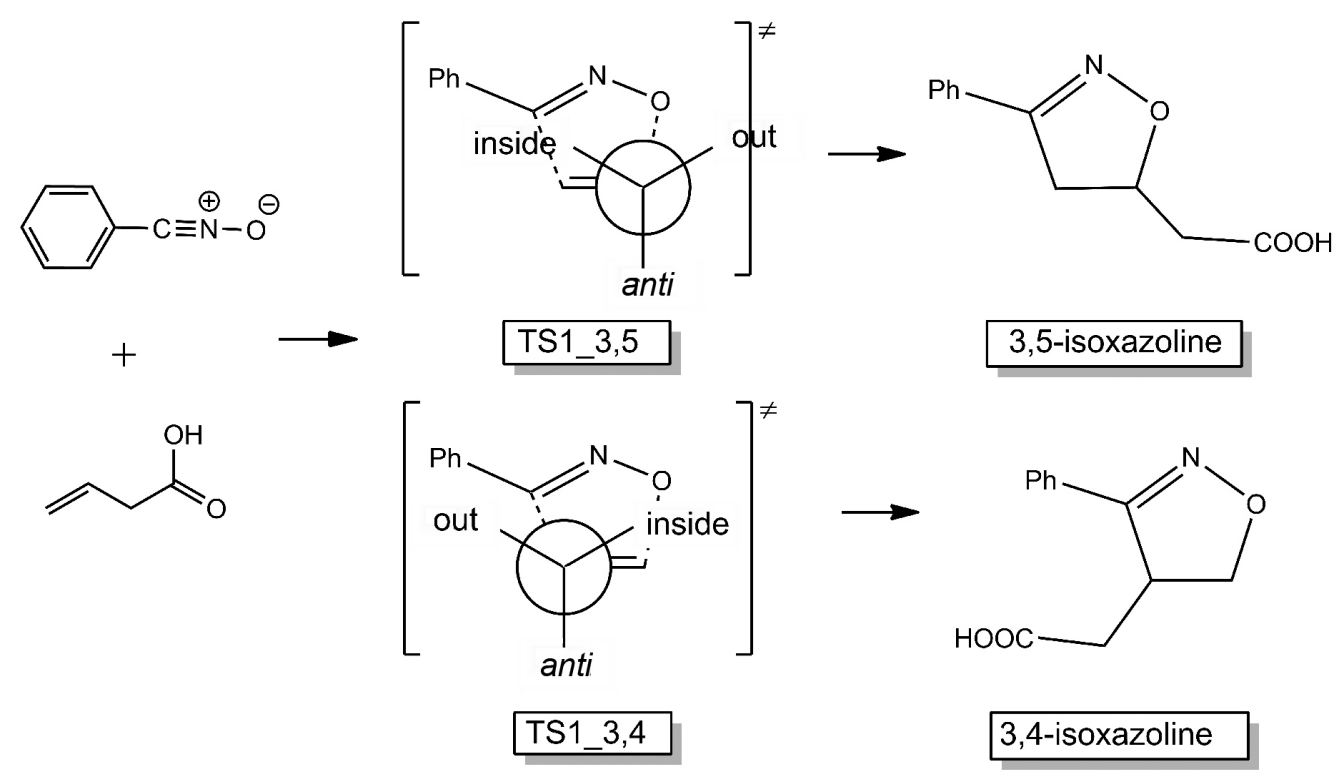

Scheme 2. Reaction scheme for the two regioisomers. Highlighted are the three possible positions for the substituent in the $\alpha$-carbon in transition structures.

The differences between the calculated activation barriers of electronic energy (in $\mathrm{kcal} \mathrm{mol}^{-1}$ ) in relation to the most stable conformer in the gas phase (TS1_3,5-anti) and in CPCM using THF as the solvent (TS1_3,5-out-HB) are shown in Table 1. The transition state geometry of TS1_3,4-out was not obtained because it turned, during the optimization, into the 3,4-anti transition state geometry.

Regarding the conformations obtained for the TS1_3,5-regioisomers, the transition structures obtained for the TS1_3,5-out, TS1_3,5-anti and TS1_3,5-in-HB show similar energy differences when solvent effects are taken into account, but TS1_3,5-out-HB, with a hydrogen bond (HB), is the most stable by $0.4 \mathrm{kcal} \mathrm{mol}^{-1}$. However, in the gas phase, there is no preference for the geometries with the hydrogen bond and the lowest energy structure became the one which has the $-\mathrm{COOH}$ group in the anti position (TS1_3,5-anti). In general, when solvent effects are taken into account, the transition states containing the hydrogen bond are stabilized. The energies obtained for the transition states that gave rise to the 3,4-regioisomer are considerably higher in both the gas phase and condensed phase. According to the $\mathrm{FMO}^{13}$ theory, the 3,5-isoxazoline product would be favored if the dipolarophile is ER, while a mix of the 3,4- and 3,5-regioisomers would be expected when ED alkenes are used because of changes in the energy levels of the FMO..$^{34,35}$ As the formation of 3,4-isoxazoline is energetically disfavored in the first cycloaddition, in the second reaction only transition structures involving the 3,5-substituted products are taken into account.

By evaluating the activation energies and also the energy of the FMO of the product generated in the 13DC and reactants, a new cycloaddition occurs. This subsequent reaction takes place between $\mathrm{BNO}$ and the monoadduct $\mathbf{3}$, producing a bicyclic molecule that is experimentally observed. ${ }^{17}$

Table 1. Differences between calculated activation barriers of electronic energy (in kcal mol-1) in relation to the most stable conformer in the gas phase (TS1_3,5-anti) and in CPCM using THF as solvent (TS1_3,5-out-HB). All the energies include ZPE corrections. Imaginary frequencies are shown in the gas phase

\begin{tabular}{|c|c|c|c|c|c|}
\hline Compound & $\Delta \Delta \mathrm{E}^{\neq a, b} /\left(\mathrm{kcal} \mathrm{mol}^{-1}\right)$ & Frequency ${ }^{\mathrm{a}} / \mathrm{cm}^{-1}$ & Inside & Outside & anti \\
\hline TS1_3,5-in & $1.2(2.3)$ & -412.8 & $\mathrm{COOH}$ & $\mathrm{H}$ & $\mathrm{H}$ \\
\hline TS1_3,5-in-HB & $1.7(0.8)$ & -413.4 & $\mathrm{COOH}$ & $\mathrm{H}$ & $\mathrm{H}$ \\
\hline TS1_3,5-anti & $0.0(0.5)$ & -405.0 & $\mathrm{H}$ & $\mathrm{H}$ & $\mathrm{COOH}$ \\
\hline TS1_3,5-out & $0.3(0.4)$ & -407.8 & $\mathrm{H}$ & $\mathrm{COOH}$ & $\mathrm{H}$ \\
\hline TS1_3,5-out-HB & $1.8(0.0)$ & -398.6 & $\mathrm{H}$ & $\mathrm{COOH}$ & $\mathrm{H}$ \\
\hline TS1_3,4-in & $4.9(5.3)$ & -439.4 & $\mathrm{COOH}$ & $\mathrm{H}$ & $\mathrm{H}$ \\
\hline TS1_3,4-anti & $2.7(3.0)$ & -422.3 & $\mathrm{H}$ & $\mathrm{H}$ & $\mathrm{COOH}$ \\
\hline TS1_3-4-out & - & - & $\mathrm{H}$ & $\mathrm{COOH}$ & $\mathrm{H}$ \\
\hline
\end{tabular}

aB3LYP/6-311+G(2d,p), gas phase; ${ }^{\mathrm{B} B} 3 \mathrm{LYP} / 6-311+\mathrm{G}(2 \mathrm{~d}, \mathrm{p})$, using CPCM and THF as solvent (in parentheses). $\Delta \Delta \mathrm{E}^{\ddagger}$ : difference between calculated activation barriers of electronic energy. 
In the second transition state (TS2), instead of adding to the double bond of an alkene, the BNO is added to the double bond in the heterocycle ring. In this sense, BNO could interact with both faces ( $\alpha$ or $\beta$ ) of the former product. The $\alpha$ face is opposed to the $-\mathrm{CH}_{2} \mathrm{COOH}$ group and the $\beta$ face is the most sterically hindered (Figure 1). In the second cycloaddition, the products corresponding to the most stable rotamers found in the first cycloaddition were considered. Thus, the calculated transition states are taken into account regarding both the relative position of the substituent group (anti and out) and the interaction by both faces ( $\alpha$ and $\beta$ ). The possibility of forming a hydrogen bond with the incoming nitrile oxide oxygen is also considered and can be seen in Figure S2 together with all TS2 structures found.

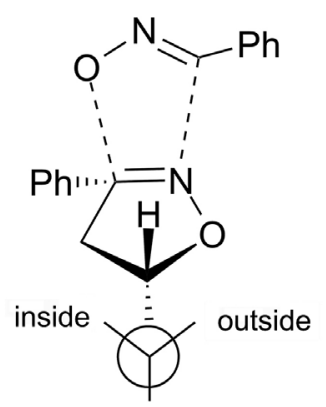

anti

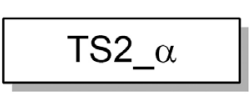

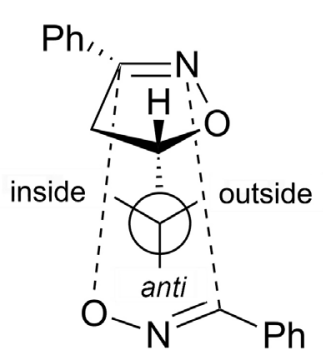

TS2_ $\beta$
Figure 1. Transition structures (schematically presented) obtained for the second cycloaddition. The 1,3-dipole approaches by the sterically less hindered face (on the right) and 1,3-dipole approaches by the sterically more hindered face (on the left).

The transition structures where BNO approaches the former product by the $\beta$ face are slightly more stable (Table 2). Regardless of the face, in the gas phase the anti rotamer is favored by more than $1.0 \mathrm{kcal} \mathrm{mol}^{-1}$. When solvent effects are taken into account, the four structures without hydrogen bonds present an electronic energy difference below $0.3 \mathrm{kcal} \mathrm{mol}^{-1}$. However, for the structures in which the attack of nitrile oxide took place via the $\beta$ face, energies are slightly lower. In addition, with the solvent effect, there is a further stabilization of the structures derived from the out rotamer, with TS2_ $\beta$-out being the most stable. This same effect is observed for TS1, where the anti rotamers are favored in the gas phase and the out rotamers are favored by solvent effects.

The TS2_ $\alpha$-out-HB and TS2_ $\beta$-out-HB structures (Figure S2) correspond to 3,5-isoxazoline products that contain an intramolecular hydrogen bond in their structures. In the gas phase, both the TS1 and their respective product (PROD1) that presented this hydrogen bond are energetically disfavored by energy differences exceeding $1.0 \mathrm{kcal} \mathrm{mol}^{-1}$. For the bicyclo formation, the structures containing this hydrogen bond are less stable, showing relative electronic energies greater than $3.0 \mathrm{kcal} \mathrm{mol}^{-1}$, in relation to the most stable structure.

When solvent effects are taken into account, this difference decreases, but it is still greater than $1.0 \mathrm{kcal} \mathrm{mol}^{-}$ ${ }^{1}$. Furthermore, TS2_ $\beta$-anti-HB, with a-COOH group in the anti position and a possible hydrogen bond with the oxygen of the nitrile oxide, shows higher energies, especially in the gas phase. This means that a more compact transition state, stabilized by a hydrogen bond, was not enough to this state be the most favorable transition state.

Reaction mechanism, comparison between functionals, and solvent effects for the first cycloaddition

Taking into account the formation of 3,5-isoxazoline and the preference of the $-\mathrm{COOH}$ group for the anti and out positions, the transition states relating to TS1_3,5-anti, TS1_3,5-out and TS1_3,5-out-HB are calculated using the three functionals proposed in this study.

Table 2. Differences between calculated activation barriers of electronic energy (in kcal mol-1) in relation to the most stable conformer in the gas phase (TS2_ $\beta$-anti) and in CPCM using THF as solvent (TS2_ $\beta$-out). All the energies include ZPE corrections. Imaginary frequencies are shown in the gas phase

\begin{tabular}{|c|c|c|c|c|c|}
\hline Compound & $\Delta \Delta \mathrm{E}^{\neq \mathrm{a}, \mathrm{b}} /\left(\mathrm{kcal} \mathrm{mol}^{-1}\right)$ & Frequency ${ }^{\mathrm{a}} / \mathrm{cm}^{-1}$ & Inside & Outside & anti \\
\hline TS2_ $\alpha$-anti & $0.7(0.3)$ & -401.1 & $\mathrm{H}$ & $\mathrm{H}$ & $\mathrm{COOH}$ \\
\hline TS2_ $\alpha$-out & $1.6(0.1)$ & -404.1 & $\mathrm{H}$ & $\mathrm{COOH}$ & $\mathrm{H}$ \\
\hline TS2_ $\alpha$-out-HB & $3.8(2)$ & -407.7 & $\mathrm{H}$ & $\mathrm{COOH}$ & $\mathrm{H}$ \\
\hline TS2_ $\beta$-anti & $0.0(0.1)$ & -397.5 & $\mathrm{H}$ & $\mathrm{H}$ & $\mathrm{COOH}$ \\
\hline TS2_ $\beta$-out & $1.1(0.0)$ & -400.6 & $\mathrm{H}$ & $\mathrm{COOH}$ & $\mathrm{H}$ \\
\hline TS2_ß-out-HB & $3.5(1.4)$ & -404.1 & $\mathrm{H}$ & $\mathrm{COOH}$ & $\mathrm{H}$ \\
\hline TS2_ß -anti-HB & $3.0(2.3)$ & -383.5 & $\mathrm{H}$ & $\mathrm{H}$ & $\mathrm{COOH}$ \\
\hline
\end{tabular}

${ }^{\mathrm{a} B} 3 \mathrm{LYP} / 6-311+\mathrm{G}(2 \mathrm{~d}, \mathrm{p})$, gas phase; ${ }^{\mathrm{b} B} 3 \mathrm{LYP} / 6-311+\mathrm{G}(2 \mathrm{~d}, \mathrm{p})$, using CPCM and THF as solvent (in parentheses). $\Delta \Delta \mathrm{E}^{ \pm}$: difference between calculated activation barriers of electronic energy. 
The traditional reaction mechanism of the $[3+2]$ 13DC is a concerted process, with only one transition state along the reaction pathway. However, this process could be a synchronous or an asynchronous process. Figure 2 depicts the main bond lengths and angles of the three most stable transition states and their related products. The formation of new bonds between $\mathrm{BNO}$ and vinylacetic acid took place asynchronously but in a coordinated way, with the bond between carbons being formed first in all transition structures. This mechanism is confirmed by IRC calculations. Thus, the reaction should start with a nucleophilic attack of the unsubstituted carbon of the alkene to the carbon atom of the 1,3-dipole producing a five membered 3,5-substituted heterocyclic ring. The distance for forming $\mathrm{C}-\mathrm{C}$ bonds is in the range of 2.18-2.22 $\AA$, while the distance of $\mathrm{C}-\mathrm{O}$ bonds is in the range of $2.29-2.49 \AA$ in the gas phase. Different DFT methods would give a slight change in the bond lengths and angles, but the differences are more pronounced for the bond order (Wiberg bond index), where PBE1PBE gives smaller values and thus more asynchronous reactions. By including the solvent effect, the values for bond lengths and angles were slightly changed: the $\mathrm{C}_{5}-\mathrm{C}_{3}$ bond decreases while $\mathrm{C}_{2}-\mathrm{O}_{3}$ bond increases. TS1_3,5-out-HB had a more asynchronous behavior than the others because of the hydrogen bond is directly involved in the transition state. The transition state synchronization is dependent on the polarity of the solvent; in general, increasing the solvent polarity, the transition state becomes asynchronous. ${ }^{68}$

Regarding the geometry of product 1 , the choice of the DFT functional shows less influence on the bond lengths and angles than in the transition state. This is because the functionals are parameterized to the ground state. In general, PBE1PBE and CAM-B3LYP presented essentially the same results, while the geometries found with B3LYP often had larger bond lengths, from 0.01-0.02 A.

Table 3 presents the activation free energies and reaction free energies for the first cycloaddition. These values are in the same order of magnitude obtained in the literature for similar reactions. ${ }^{24,34,35,37,69}$ In fact, cycloadditions involving benzonitrile oxide proceed smoothly even with completely unactivated dipolarophiles, such as ethene, under ordinary laboratory conditions. ${ }^{70}$ Considering the three functionals, the lowest activation free energies $\left(26.2\right.$ - $\left.28.7 \mathrm{kcal} \mathrm{mol}^{-1}\right)$ were obtained using PBE1PBE, while CAM-B3LYP and B3LYP produced very similar barriers $\left(29.5-32.2 \mathrm{kcal} \mathrm{mol}^{-1}\right)$. However, the transition structure presenting the lowest electronic energy and lowest free activation barrier, in the gas phase, was TS1_3,5-anti (by up to $0.5 \mathrm{kcal} \mathrm{mol}^{-1}$ ). When solvent effects were considered, the TS1_3,5-out-HB was stabilized and the $\Delta \mathrm{G}^{\neq}$decreases significantly and all the three structures have

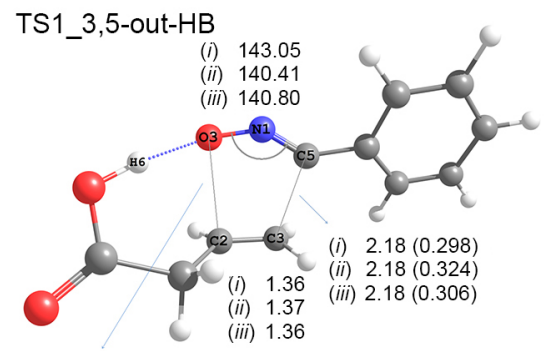

(i) $2.49(0.169)$

(ii) $2.45(0.190)$

(iii) $2.37(0.190)$

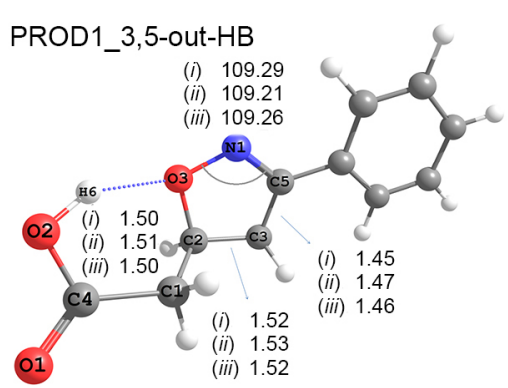

TS1_3,5-out
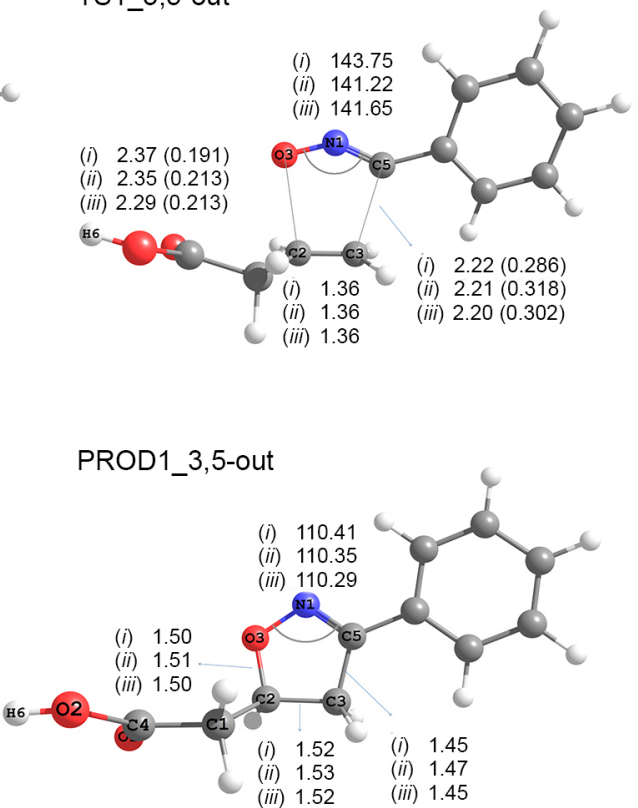
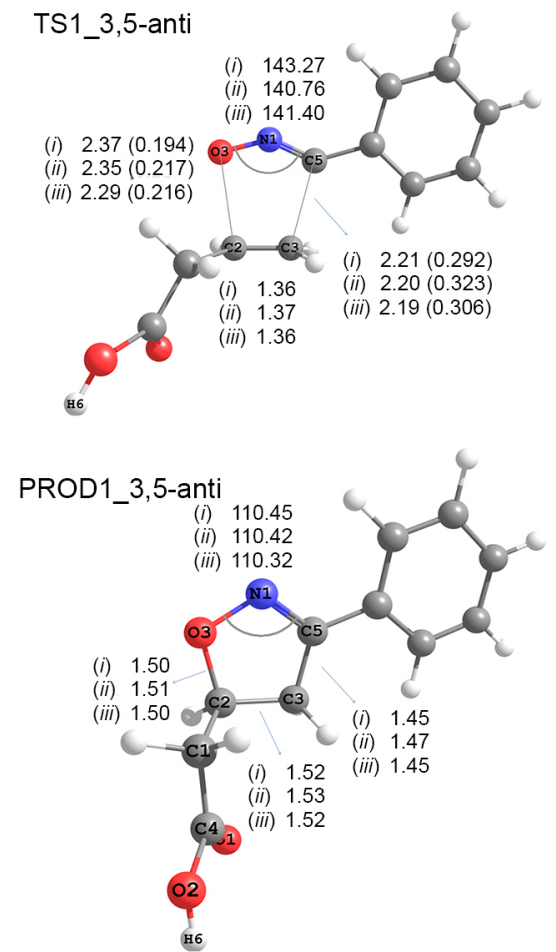

Figure 2. Geometries of lower energy transition structures for the first cycloaddition (TS1) and corresponding products obtained in the gas phase,showing the new bond lengths formed andrespective Wiberg bond index (in parentheses), the angles between $\mathrm{C} 5-\mathrm{N} 1-\mathrm{O} 3$ and the $\mathrm{C} 2-\mathrm{C} 3$ bond lengths. The functionals used are: (i) PBE1PBE, (ii) B3LYP and (iii) CAM-B3LYP. All bond lengths are in $\AA$ and angles in degrees. 
Table 3. Activation free energies (in $\mathrm{kcal} \mathrm{mol}^{-1}$ ), and corresponding reaction free energies (given in parentheses, in $\mathrm{kcal}^{\mathrm{mol}}{ }^{-1}$ ) at $298.15 \mathrm{~K}_{\text {for the reaction }}$ between benzonitrile oxide and vinylacetic acid. All geometries are optimized using 6-311+G(2d,p) basis set

\begin{tabular}{lccccccc}
\hline \multicolumn{7}{c}{} & \multicolumn{5}{c}{$\Delta \mathrm{G}^{\neq}\left(\Delta \mathrm{G}_{\mathrm{rxn}}\right) /\left(\mathrm{kcal} \mathrm{mol}{ }^{-1}\right)$} \\
\cline { 2 - 8 } & Gas phase & CPCM THF & PCM THF & CPCM ACN & PCM ACN & CPCM FORM & PCM FORM \\
\hline 3,5-out & & & & & & & \\
PBE1PBE & $26.86(-28.89)$ & $27.67(-28.98)$ & $27.96(-28.75)$ & $27.76(-29.01)$ & $27.43(-28.96)$ & $28.00(-29.03)$ & $27.98(-29.00)$ \\
B3LYP & $30.00(-17.73)$ & $31.05(-17.95)$ & $31.30(-17.79)$ & $31.19(-17.94)$ & $31.29(-17.84)$ & $31.18(-17.87)$ & $31.22(-17.91)$ \\
CAM-B3LYP & $30.38(-26.97)$ & $31.73(-26.74)$ & $32.08(-26.74)$ & $32.06(-26.70)$ & $32.05(-26.70)$ & $32.08(-26.71)$ & $32.10(-26.71)$ \\
\hline 3,5-out-HB & & & & & & & \\
PBE1PBE & $28.66(-26.88)$ & $28.08(-27.84)$ & $28.52(-27.59)$ & $27.80(-28.02)$ & $27.70(-27.94)$ & $27.67(-28.05)$ & $27.65(-28.02)$ \\
B3LYP & $32.13(-15.54)$ & $31.39(-16.56)$ & $31.75(-16.30)$ & $31.22(-16.73)$ & $31.28(-16.67)$ & $31.18(-16.77)$ & $31.20(-16.74)$ \\
CAM-B3LYP & $32.19(-25.03)$ & $31.86(-25.78)$ & $31.91(-25.78)$ & $31.62(-25.92)$ & $31.69(-25.92)$ & $31.53(-25.94)$ & $31.56(-25.94)$ \\
\hline 3,5-anti & & & & & & & \\
PBE1PBE & $26.21(-29.88)$ & $27.47(-29.06)$ & $27.66(-28.90)$ & $27.59(-28.92)$ & $27.65(-28.87)$ & $27.64(-28.89)$ & $27.66(-28.87)$ \\
B3LYP & $29.48(-18.96)$ & $30.96(-18.08)$ & $31.21(-17.89)$ & $31.14(-17.88)$ & $31.24(-17.84)$ & $31.18(-17.83)$ & $31.22(-16.77)$ \\
CAM-B3LYP & $29.87(-28.08)$ & $31.65(-26.85)$ & $32.01(-26.85)$ & $31.77(-26.62)$ & $31.96(-26.62)$ & $31.78(-26.58)$ & $31.86(-26.58)$ \\
\hline
\end{tabular}

$\Delta \mathrm{G}^{\neq}$: activation free energy; $\Delta \mathrm{G}_{\mathrm{rxx}}$ : reaction free energy; CPCM: conductor-like polarizable continuum model; THF: tetrahydrofuran; PCM: polarizable continuum model; ACN: acetonitrile; FORM: formamide.

lower free energy barriers by approximately $1.0 \mathrm{kcal} \mathrm{mol}^{-1}$. A clear visualization of the variation in energy involving the different functionals with solvent addition and an extended discussion can be found in Supplementary Information (Figure S3).

13DC reactions are described as not being very sensitive to changes in solvent polarity. ${ }^{46} \mathrm{~A}$ slight increase in the activation energy occurs when solvent effects are considered. This is observed in all transition states computed for the first cycloaddition, except for those that exhibit hydrogen bond. This small energy variation is consistent with that reported in the literature, ${ }^{36}$ indicating that $13 \mathrm{DC}$ reactions may show a reverse dependence in the reaction rate and the polarity of the medium, and may be slower in polar aprotic media. ${ }^{36,71,72} \mathrm{An}$ increase in the solvent dielectric constant produces essentially identical activation barriers for all structures. This could be explained by the less polar transition state when compared to the reagents. ${ }^{73}$ The change in polarity along the reaction path could be observed by comparing the sum of the dipole moments of the reagents with the dipole moments obtained for the transition states (Table S1). In fact, the energy of TS1_3,5-out-HB is slightly decreased by the inclusion of solvent effects while for the other TS1, this value is negative, indicating a lower polarity of the reagents in relation to the transition state. This could explain the observed differences in activation free energies. In general, a tendency could be observed in change of polarity: if the transition state is more polar than the reactants $(\Delta \mu>0)$, an increase in the solvent polarity should cause a decrease in the activation energy due to greater stabilization of the transition structure. ${ }^{71}$

Reaction free energies $\left(\Delta \mathrm{G}_{\mathrm{rxn}}\right)$ are shown in parentheses in Table 3 and better visualized in Figure S4. In the gas phase, the most stable structure (and also the most exergonic) is PROD1_3,5-anti, which contains a carboxyl group at the anti position. When solvent effects were taken into account, the structure with the carboxyl group in the out position was stabilized and this effect increases with the increment of the solvent dielectric constant. In addition, PROD1_3,5-anti and PROD1_3,5-out had very similar energies. On the other hand, PROD1_3,5-out-HB had a significantly higher reaction free energy, especially in the gas phase.

The reaction free energies obtained are significantly different between the considered functionals. The B3LYP functional provided much higher reaction free energy ranging from -19.0 to $-15.5 \mathrm{kcal} \mathrm{mol}^{-1}$, while the PBE1PBE provided $\Delta \mathrm{G}_{\mathrm{rxn}}$ in the range of -29.9 to $-26.9 \mathrm{kcal} \mathrm{mol}^{-1}$ and CAM-B3LYP provided $\Delta \mathrm{G}_{\mathrm{rxn}}$ in the range of -28.0 to $-25.0 \mathrm{kcal} \mathrm{mol}^{-1}$.

The activation enthalpies, entropies and electronic energy of the first cycloaddition are reported in Table S2. The electronic energy barriers and enthalpy barriers are very close. However, the entropy effect produces an increment on the free activation barriers and lower free energies of the reactions. The entropic effect is on the order of -39.0 to $-46.0 \mathrm{cal} \mathrm{mol}^{-1} \mathrm{~K}^{-1}$ for the activation barriers and for the reaction energies it is on the order of -46 to $-52 \mathrm{cal} \mathrm{mol}^{-1} \mathrm{~K}^{-1}$. In general, the 1,3-dipolar cycloaddition reactions presented 
a highly negative entropy of activation. ${ }^{74}$ This indicates a high degree of order requirement in the transition state. The low activation energy implies a transition state that resembles the reactants. Since the 13DC cycloaddition reaction involving a nitrile oxide requires a great distortion in the 1,3-dipole structure to enable the overlap between the orbitals in transition state, the transition state is more similar to the product. Thus, these reactions have a moderate free energy requirement.

In order to compare the results obtained using DFT, CCSD(T) calculations were performed using B3LYP/6-311+G(2d,p) geometries in the first cycloaddition and solvent effects were included by using CPCM/THF (Table 4). The activation electronic energies produced are $10.3 \mathrm{kcal} \mathrm{mol}^{-1}$ (TS1_3,5-out), $10.75 \mathrm{kcal}^{\mathrm{mol}}{ }^{-1}$ (TS1_3,5-out-HB) and $10.78 \mathrm{kcal} \mathrm{mol}^{-1}$ (TS1_3,5-anti). The electronic barriers (without ZPE corrections) obtained with the PBE1PBE calculations are equal to $15.2 \mathrm{kcal} \mathrm{mol}^{-1}$ (TS1_3,5-out), $14.5 \mathrm{kcal} \mathrm{mol}^{-1}$ (TS1_3,5-out-HB) and $15.4 \mathrm{kcal} \mathrm{mol}^{-1}$ (TS1_3,5-anti). B3LYP and CAM-B3LYP presented larger electronic barriers of $17.8-18.9 \mathrm{kcal} \mathrm{mol}^{-1}$. Although all the functionals has shown considerable errors when compared to $\operatorname{CCSD}(\mathrm{T})$ calculations, PBE1PBE showed a better agreement. Whereas $\operatorname{CCSD}(\mathrm{T})$ calculations pointed to TS1_3,5-out as the most stable transition state, all DFT calculations pointed to TS1_3,5-out-HB as the most stable TS1. The reaction electronic energy obtained with $\operatorname{CCSD}(\mathrm{T})$ for the most stable product (PROD1_3,5-out) is $-48.3 \mathrm{kcal} \mathrm{mol}^{-1}$. In comparison, the reaction electronic energies obtained with DFT methods are
$-46.5 \mathrm{kcal} \mathrm{mol}^{-1}$ (PBE1PBE), $-35.1 \mathrm{kcal} \mathrm{mol}^{-1}$ (B3LYP) and $-44.2 \mathrm{kcal} \mathrm{mol}^{-1}$ (CAM-B3LYP). These results suggest that, compared to $\operatorname{CCSD}(\mathrm{T})$ calculations, PBE1PBE provides better electronic barriers and reaction energies.

The regioselectivity of system can be explained by the frontier molecular orbitals analysis. Concerted 1,3-dipolar cycloaddition reactions are classified by Sustmann into three categories depending on the dominant type of interaction between the FMO of the dipole and dipolarophile. ${ }^{3}$ Reactions of type I are controlled by the interaction between $\mathrm{HOMO}_{\text {dipole }}$ and $\mathrm{LUMO}_{\text {dipolarophile }}$ and those of type III are controlled by the $\mathrm{LUMO}_{\text {dipole }}$ and $\mathrm{HOMO}_{\text {dipolarophile }}$ interaction, while type II are controlled by both types of interaction. Considering the energy gaps of the first cycloaddition, in the gas phase at the B3LYP/6-311+G(2d,p) level, the energy gap for the type I interaction is $6.40 \mathrm{eV}$ whereas for the type III interaction it is $5.78 \mathrm{eV}$. It is important to note that the isoxazoline produced in this reaction has a HOMO orbital with higher energy and a LUMO orbital with lower energy than vinylacetic acid, which explains the regioselectivity of the second cycloaddition. The gap type III for this reaction is equal to $4.63 \mathrm{eV}$. In this way, the analysis of the frontier molecular orbitals suggests that both the cycloaddition reactions are type III, since the energy gap is smaller for this interaction.

The 13DC reaction is often accompanied by bending of the benzonitrile oxide molecule. This bending leads to an increase in the HOMO energy and a decrease in the LUMO energy in the 1,3-dipole, according to the distortion/ interaction model developed by Ess and Houk. ${ }^{75,76}$

Table 4. Calculated electronic energy (without ZPE), enthalpy, free energy ( $\mathrm{kcal} \mathrm{mol}^{-1}$ ), and entropies (cal mol ${ }^{-1} \mathrm{~K}^{-1}$ ) obtained at $298.15 \mathrm{~K}_{\text {for the first }}$ cycloaddition using THF as solvent and CPCM as continuum model

\begin{tabular}{|c|c|c|c|c|c|c|c|c|c|}
\hline & \multirow{2}{*}{ Method } & \multicolumn{4}{|c|}{ Activation energy / $\left(\mathrm{kcal} \mathrm{mol}^{-1}\right)$} & \multicolumn{4}{|c|}{ Reaction energy / $\left(\mathrm{kcal} \mathrm{mol}^{-1}\right)$} \\
\hline & & $\Delta \mathrm{E}_{\mathrm{e}}^{\neq}$ & $\Delta \mathrm{H}^{\mp}$ & $\Delta \mathrm{G}^{ \pm}$ & $\Delta \mathrm{S}^{\neq \mathrm{a}}$ & $\Delta \mathrm{E}_{\mathrm{rxn}}^{\mathrm{e}}$ & $\Delta \mathrm{H}_{\mathrm{rxn}}$ & $\Delta \mathrm{G}_{\mathrm{rxn}}$ & $\Delta \mathrm{S}_{\mathrm{rxn}}{ }^{\mathrm{a}}$ \\
\hline \multirow{4}{*}{ TS1_3,5-anti/PROD1_3,5-anti } & $\mathrm{PBE} \mathrm{PBE}^{\mathrm{b}}$ & 15.38 & 14.15 & 26.21 & -40.47 & -46.42 & -43.31 & -29.06 & -47.79 \\
\hline & $\mathrm{B} 3 \mathrm{LYP}^{\mathrm{b}}$ & 18.56 & 18.93 & 30.96 & -40.36 & -35.03 & -31.98 & -18.08 & -46.66 \\
\hline & CAM-B3LYP & 19.22 & 19.61 & 31.65 & -40.40 & -44.17 & -40.97 & -26.85 & -47.39 \\
\hline & $\operatorname{CCSD}(T)^{c}$ & 10.78 & - & - & - & -48.62 & - & - & - \\
\hline \multirow{4}{*}{ TS1_3,5-out/PROD1_3,5-out } & PBE1PBE $^{b}$ & 15.22 & 15.51 & 27.67 & -40.83 & -46.49 & -43.35 & -28.98 & -48.23 \\
\hline & B3LYP & 18.47 & 18.80 & 31.05 & -41.11 & -35.14 & -32.08 & -17.95 & -47.41 \\
\hline & CAM-B3LYP & 18.95 & 19.31 & 31.73 & -41.65 & -44.23 & -41.02 & -26.74 & -47.92 \\
\hline & $\operatorname{CCSD}(T)^{c}$ & 10.30 & - & - & - & -48.29 & - & - & - \\
\hline \multirow{4}{*}{ TS1_3,5-out-HB/PROD1_3,5-out-HB } & $\mathrm{PBE} \mathrm{PBE}^{\mathrm{b}}$ & 14.52 & 14.78 & 28.08 & -44.61 & -46.43 & -43.17 & -27.84 & -51.42 \\
\hline & $\mathrm{B}^{2} \mathrm{LYP}^{\mathrm{b}}$ & 17.81 & 18.13 & 31.39 & -44.49 & -35.02 & -31.80 & -16.56 & -51.13 \\
\hline & CAM-B3LYP & 18.07 & 18.45 & 31.86 & -45.01 & -44.36 & -40.98 & -25.78 & -51.01 \\
\hline & $\operatorname{CCSD}(T)^{c}$ & 10.75 & - & - & - & - & - & - & - \\
\hline
\end{tabular}

${ }^{\mathrm{a}} \mathrm{cal} \mathrm{mol}{ }^{-1} \mathrm{~K}^{-1}$; ${ }^{b} \mathrm{DFT}$ calculations are done at 6-311+G(2d,p) level; ${ }^{\mathrm{c} C C S D}(\mathrm{~T}) / 6-311+\mathrm{G}(2 \mathrm{~d}, \mathrm{p}) / / \mathrm{B} 3 \mathrm{LYP} / 6-311+\mathrm{G}(2 \mathrm{~d}, \mathrm{p}) . \Delta \mathrm{E}_{\mathrm{e}}{ }^{\neq}, \Delta \mathrm{H}^{\ddagger}, \Delta \mathrm{G}^{\neq}, \Delta \mathrm{S}^{\neq}$: electronic energy, enthalpy, free energy, and entropy of activation, respectively; $\Delta \mathrm{E}_{\mathrm{rxn}}^{\mathrm{e}}, \Delta \mathrm{H}_{\mathrm{rxn}}, \Delta \mathrm{G}_{\mathrm{rxn}}, \Delta \mathrm{S}_{\mathrm{rxx}}$ : electronic energy, enthalpy, free energy, and entropy of reaction, respectively. 
Dipolarophiles are slightly distorted, thus only a slight increase in the HOMO energy and decrease in the LUMO energy are observed. ${ }^{77}$ The distortion of both reactants provides a more effective type III interaction. For the first cycloaddition, this gap is $4.63 \mathrm{eV}$ and for the second cycloaddition, the energy gap is equal to $3.41 \mathrm{eV}$. The frontier molecular orbitals of the reactions are shown in Figure 3.

Reaction mechanism, comparison between functionals, and solvent effects for the second cycloaddition

The second dipolar cycloaddition proceeds from the addition of $\mathrm{BNO}$ to the $\mathrm{C}=\mathrm{N}$ bond of isoxazoline (PROD1), also in a concerted but asynchronous way. ${ }^{30}$ The $2: 1$ cycloadduct obtained is due to the higher reactivity of the $\mathrm{C}=\mathrm{N}$ bond of $\mathbf{3}$. The four structures with lower energy found for the TS2 are shown in Figure 4. For bisadduct formation, the electrophilic carbon of the dipole attacks the nitrogen of the heterocyclic ring (nucleophilic center) and the oxygen, in turn, provides electronic density to the pro-chiral carbon attached to the aromatic ring.

The second cycloaddition is more asynchronous than the first one. When the 1,3-dipole addition occurs, in the gas phase, via the $\beta$ face, the reaction is even more asynchronous since the $\mathrm{C}_{6}-\mathrm{N}_{1}$ bond length is in the range of 1.92-1.94 $\AA$ and the $\mathrm{C}_{5}-\mathrm{O}_{4}$ is in the range of 2.45-2.58 $\AA$. On $\alpha$ face attack, the $\mathrm{C} 6-\mathrm{N} 1$ bond length is in the range of 1.94-1.97 $\AA$ and the C5-O4 is in the range of 2.36-2.49. This could be explained by the stronger electron repulsion in the structures whose attack by BNO occurred on the same side as the $-\mathrm{COOH}$ group ( $\beta$ face attack). Again, the different DFT functionals considered in this work presented slight changes in the bond lengths and angles, but with higher differences in bond orders (Wiberg bond index). When solvent effects were included, the $\mathrm{C}_{5}-\mathrm{O}_{4}$ bond length increased to 2.51-2.75 $\AA$ while $\mathrm{C}_{6}-\mathrm{N}_{1}$ decreased to 1.91-1.95 $\AA$, making the reaction even more asynchronous.

The $\mathrm{C}_{6}-\mathrm{N}_{1}$ bond length is less sensitive to functional changes and to the inclusion of solvent effects. In the same

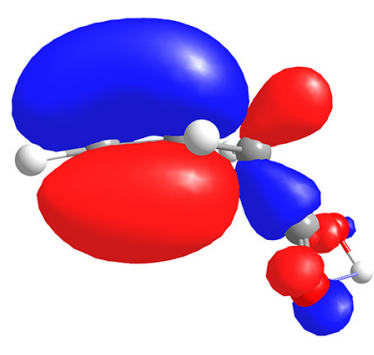

$\mathrm{HOMO}_{\text {dipolarophile(TS1) }}$

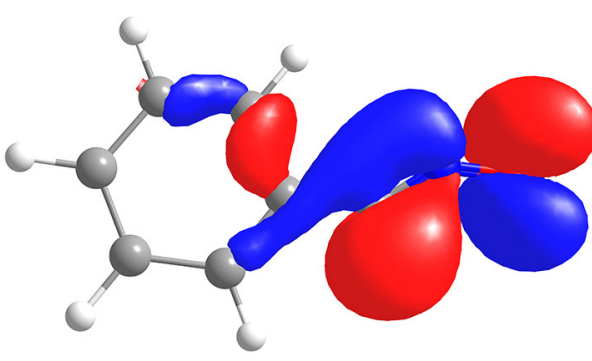

$\mathrm{LUMO}_{\text {dipole }}$

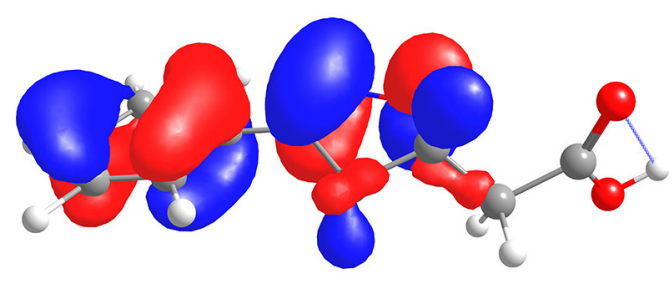

$\mathrm{HOMO}_{\text {dipolarophile(TS2) }}$

Figure 3. Frontier molecular orbitals (in the TS geometry) involved in the two cycloaddition reactions.
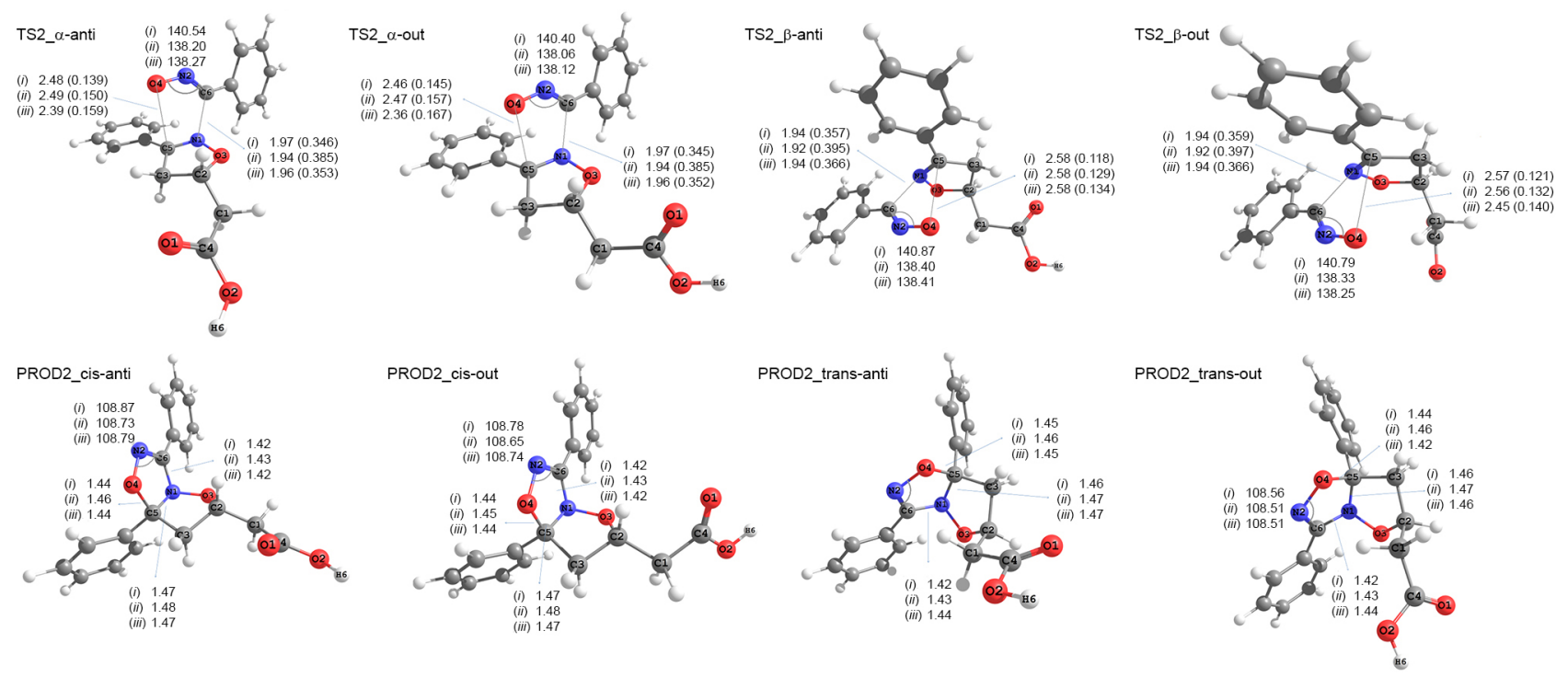

Figure 4. Geometries of lower energy transition structures for the second cycloaddition(TS2) and corresponding products obtained in the gas phase, showing the new bond lengths formed and respective Wiberg indices (in parentheses), and angles between C5-N1-O3. The functionals used are: (i) PBE1PBE, (ii) B3LYP and (iii) CAM-B3LYP. All bond lengths are in $\AA$ and angles in degrees 
Table 5. Calculated free energy barriers and reaction free energies $\left(\mathrm{kcal} \mathrm{mol}^{-1}\right)$ obtained at $298 \mathrm{~K}$ for the second cycloaddition, in the gas phase and THF, using CPCM as solvent model.

\begin{tabular}{|c|c|c|c|c|c|c|c|c|c|}
\hline \multirow[t]{2}{*}{ Functional } & \multirow[t]{2}{*}{ Solvent } & \multicolumn{2}{|c|}{$\begin{array}{l}\text { TS2_ } \alpha \text {-anti/ } \\
\text { PROD2_cis-anti / } \\
\left(\mathrm{kcal} \mathrm{mol}^{-1}\right)\end{array}$} & \multicolumn{2}{|c|}{$\begin{array}{l}\text { TS2_ } \alpha \text {-out/ } \\
\text { PROD2_cis-out / } \\
\left(\mathrm{kcal} \mathrm{mol}{ }^{-1}\right)\end{array}$} & \multicolumn{2}{|c|}{$\begin{array}{c}\text { TS2_ } \beta \text {-out/ } \\
\text { PROD2_trans-out / } \\
\left(\mathrm{kcal} \mathrm{mol}^{-1}\right)\end{array}$} & \multicolumn{2}{|c|}{$\begin{array}{c}\text { TS2_ß-anti/ } \\
\text { PROD2_trans-anti / } \\
\left(\mathrm{kcal} \mathrm{mol}{ }^{-1}\right)\end{array}$} \\
\hline & & $\Delta \mathrm{G}^{\neq}$ & $\Delta \mathrm{G}_{\mathrm{rxn}}$ & $\Delta \mathrm{G}^{\neq}$ & $\Delta \mathrm{G}_{\mathrm{rxn}}$ & $\Delta \mathrm{G}^{ \pm}$ & $\Delta \mathrm{G}_{\mathrm{rxn}}$ & $\Delta \mathrm{G}^{\neq}$ & $\Delta \mathrm{G}_{\mathrm{rxn}}$ \\
\hline \multirow{4}{*}{ B3LYP } & gas phase & 32.51 & 2.12 & 32.35 & 2.59 & 32.92 & 4.19 & 32.30 & 3.69 \\
\hline & THF & 34.51 & 4.69 & 33.95 & 5.01 & 34.33 & 7.43 & 34.25 & 7.54 \\
\hline & acetonitrile & 34.91 & 5.63 & 34.06 & 5.65 & 34.68 & 8.07 & 34.93 & 8.31 \\
\hline & formamide & 34.91 & 5.75 & 34.02 & 5.68 & 34.67 & 8.11 & 35.00 & 8.38 \\
\hline \multirow{2}{*}{ PBE1PBE } & gas phase & 28.73 & -9.18 & 29.62 & -8.51 & 28.15 & -7.07 & 28.27 & -7.89 \\
\hline & THF & 30.45 & -6.12 & 30.43 & -6.50 & 30.61 & -4.71 & 30.66 & -4.40 \\
\hline \multirow{2}{*}{ CAM-B3LYP } & gas phase & 30.96 & -9.46 & 31.45 & -8.68 & 31.36 & -7.08 & 30.64 & -7.94 \\
\hline & THF & 33.56 & -5.51 & 33.19 & -5.71 & 33.29 & -3.65 & 33.35 & -3.56 \\
\hline
\end{tabular}

$\Delta \mathrm{G}^{\neq}$: free energy barrier; $\Delta \mathrm{G}_{\mathrm{rxn}}$ : reaction free energy; THF: tetrahydrofuran.

way as for the cycloadduct formed in the first cycloaddition, the bond lengths and angles, in general, showed slight changes when compared between different structures and between different functionals. Considering the three functionals, B3LYP presented bond lengths about $0.01 \AA$ longer than the others, while the PBE1PBE and CAMB3LYP had roughly the same values.

Table 5 presents the activation free energies and reaction free energies obtained for the most stable structures found for the second cycloaddition. The activation free energies obtained are in the range of 28.1 to $30.7 \mathrm{kcal} \mathrm{mol}^{-1}$ (PBE1PBE), 32.3 to $35.0 \mathrm{kcal} \mathrm{mol}^{-1}$ (B3LYP) and 30.6 to $33.6 \mathrm{kcal} \mathrm{mol}^{-1}$ (CAM-B3LYP). With the inclusion of solvent effects, the free activation barriers are increased by around $2.0 \mathrm{kcal} \mathrm{mol}^{-1}$. Thus, the activation free energy for the second 13DC is higher than the energy for the first one. However, the cycloadduct $\mathbf{3}$ was not observed experimentally and only the bisadduct 4 was obtained. ${ }^{17}$ One possible explanation is the higher thermodynamic stability of the bisadduct, compared to cycloadduct, in addition to the slight difference in activation barriers (Figure 5).

In the same way, the FMO could explain the reactivity and regioselectivity of the system based on HOMO/LUMO interactions. The 3,5-regioisomer, formed in the first 13DC, had a HOMO higher in energy than the HOMO of vinylacetic acid and, therefore, a competition between these two species is started. A new cycloaddition between HOMO of the PROD1 and LUMO of the nitrile oxide takes place. This reaction produces a bicyclo, which is experimentally observed. ${ }^{17}$

The three DFT functionals produce approximately the

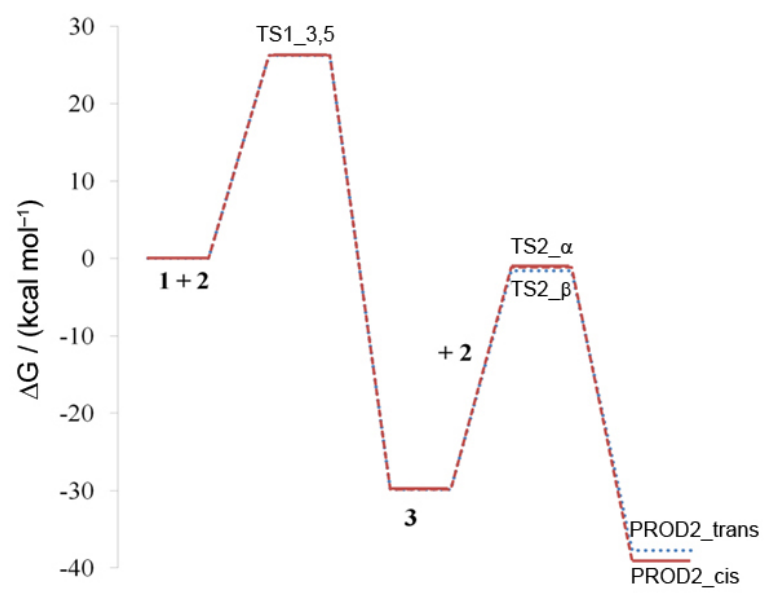

Figure 5. Free energy profile (in kcal mol-1) for the two subsequent cycloadditions in the gas phase, using PBE1PBE as functional. The energies of TS1 and PROD1 are related to $\mathbf{1}+\mathbf{2}$. The energies of TS2 and PROD2 are related to $\mathbf{3}+\mathbf{2}$.

same free energies and electronic energies for the TS2, except for TS2_ $\beta$-anti-HB.

In this transition structure, a significant change in energy could be found: the CAM-B3LYP functional stabilized the transition state more than the other functionals (Figure S5). However, it is evident that each functional provided a significant difference in the magnitude of the free energy barrier of activation.

In the second 13DC reaction, the solvent inclusion changes the reaction selectivity. In the gas phase, $\beta$ face attack is favored. The TS2_ $\beta$-out structure presents a lower activation free energy than the other structures, but this preference is very small. This small difference is also observed when considering the solvent effects, but in this case, the structure that presented the lowest $\Delta \mathrm{G}^{\ddagger}$ comes 
from the $\alpha$ face (TS2_ $\alpha$-out), while the structures from $\beta$ face have smaller electronic energies. In addition, the TS2 structure that contains a hydrogen bond in the TS (TS2_ $\beta$-anti-HB) is widely destabilized. In fact, using THF, the four structures containing no hydrogen bonds presented energy differences lower than $0.5 \mathrm{kcal} \mathrm{mol}^{-1}$.

The most significant stabilization by the solvent effects occurred in the structures containing a hydrogen bond (Figure S5). The highest polarity presented by these structures accounts for their greater stability. The transition states that did not contain a hydrogen bond shows a lower dipole moment. Furthermore, the anti structures are less polar than the out structures and, consequently, the latter are stabilized by the inclusion of the solvent effects. In the same way, the highest stabilization of the bicyclo structures containing hydrogen bonds (PROD2_cis-out-HB and PROD2_trans-out-HB) by inclusion of solvent effects could be explained by the more polar nature of these structures.

The possible geometries for the 2:1 bisadduct formed from the second cycloaddition were computed considering the attack by $\alpha$ and $\beta$ faces and the different rotamers (anti, out and out-HB). When breaking the double bond of the isoxazoline ring during TS2 formation, a loss of planarity in the five-membered ring will take place. Thus, the interconversion among the envelope and half-chair conformation $^{78}$ for this ring has also been considered. The envelope conformation with the $\mathrm{C}_{2}$ atom out of the plane is more stable than with $\mathrm{O}_{3}$ out of the plane due to electronic repulsion between aromatic ring and substituent group at the 5-position.

Table 5 also shows the reaction free energies obtained for the four more stable rotamers presented in Figure 4. The cis and trans structures refer to the relative orientation between the aromatic ring attached to $\mathrm{C} 5$ of the isoxazoline and the $-\mathrm{CH} 2 \mathrm{COOH}$ substituent group. Thus, the cis structures, come from the $\alpha$-transition states, are more stable than trans structures that come from the $\beta$-transition states. In general, the anti rotamers exhibit lower electronic energy in the gas phase, while out rotamers are stabilized with the inclusion of the solvent effect. The bicyclo conformation with hydrogen bond exhibits higher energies, especially those with hydrogen bonds directly involved in TS2.

The second cycloaddition is less exergonic than the first one, but the product obtained is thermodynamically more stable. Whereas in the first cycloaddition the $\Delta \mathrm{G}_{\mathrm{rxn}}$ magnitude is from -16.0 to $-30.0 \mathrm{kcal} \mathrm{mol}^{-1}$, in the second cycloaddition $\Delta \mathrm{G}_{\mathrm{rxn}}$ presents energies from -9.5 to $8.4 \mathrm{kcal} \mathrm{mol}^{-1}$. Again, the great dependence on the DFT functional used is observed. The B3LYP functional provides positive reaction energies. Thus, it is evident that this functional does not describe this reaction satisfactorily. PBE1PBE and CAM-B3LYP provided similar values of reaction free energy, especially in the gas phase, where these values are almost the same. In addition, those structures formed by $\alpha$ face attack had lower reaction free energies in the gas phase, and this difference increased with the inclusion of the solvent. Then, in all cases, the $\Delta \Delta \mathrm{G}_{\mathrm{rxn}}$ between both attacks shows values greater than $1.0 \mathrm{kcal} \mathrm{mol}^{-1}$.

In the gas phase, the lowest free energy barrier is obtained for TS2_ $\beta$-out, but the product with the lowest reaction free energy comes from TS2_ $\alpha$-out, i.e., PROD2_cis-out. The energy differences in relation to the attack by the other face are very close. In this way, it appears that the majority reaction product depends on the factors that control cycloadditions: kinetic or thermodynamic. In contrast to Diels-Alder reactions, which are known to be under kinetic control, ${ }^{46,78-80}$ it is not clear if 13DC reactions have kinetic control or thermodynamic control. ${ }^{80}$ However, experimental $^{81}$ and theoretical ${ }^{24,82}$ studies involving nitrile oxides point to mechanisms controlled in a kinetic way. Furthermore, it has also been reported that a preference for $\beta$ face attack, which is more sterically hindered due to torsional factors (such as a preference for staggered conformations and for the concave face of the envelope conformation in cyclopentene rings $)^{83}$ has more relevance than steric factors and governs stereoselectivity in several cases. ${ }^{84}$ From the electronic energies obtained for the TS2 and PROD2 structures (Table S4), TS2_ $\beta$ is more stable than TS2_ $\alpha$, but the product formed by TS2_ $\alpha$ is more stable.

Considering that the formation of cis and trans isomers are close in energy, we could expect to obtain a mixture of the stereoisomers. However, experimentally, only the trans isomer was isolated. No spectroscopic evidence for the formation of cis cycloadduct was obtained. The structural characterization of the bicyclo was made by ${ }^{1} \mathrm{H},{ }^{13} \mathrm{C}$ nuclear magnetic resonance (NMR) spectroscopic techniques (H,H-correlation spectroscopy (COSY), heteronuclear multiple quantum coherence (HMQC) and heteronuclear multiple bond coherence (HMBC)), electron ionization mass spectrometry (EI-MS) and high-resolution mass spectrometry (HRMS) (electrospray ionization (ESI)). These results was compared to those obtained by Caramela and co-workers ${ }^{85}$ and Jonas and co-workers, ${ }^{86}$ for the same class of bisadduct, confirming the formation of the bisadduct trans. The differences found between theoretical and experimental data could be associated with the alcoxy group bonded at para position in benzonitrile oxide (synthesized compound) or even to an error associated with the DFT functional parametrization. This topic remains open and will be subject to further studies with new isoxazolines reaction formation. 


\section{Secondary interactions between orbitals}

As well as the preference of alkoxy groups for the inside position, ${ }^{66}$ the preference for the anti position in the gas phase and the out position when including solvent effects could be explained in terms of the secondary interactions between orbitals. In this way, the charge and natural population analysis of atoms could provide a good estimate of how nucleophilic or electrophilic it is. Figure 6 shows the natural charges of atoms in the three transition state structures that resulted in 3,5-isoxazoline.

The changes in the atomic charges could be related to the secondary interaction between orbitals. In TS1_3,5-anti, the $-\mathrm{COOH}$ group preferred the anti position to stabilize the transition structure through the hyperconjugation effect. The overlap between $\pi_{\mathrm{C}=\mathrm{C}}$ and $\sigma{ }_{\mathrm{C}-\mathrm{COOH}}$ decreases the electron density in the alkene region. Thus, the HOMO energy is also reduced, similar to what happens when a withdrawing substituent group is connected to an alkene. ${ }^{13}$ The dihedral angle formed with the incoming nitrile oxide oxygen is $145.8^{\circ}$, thus the overlap between atomic orbitals is reduced and, in this way, the electron density in the double bond region is reduced. Despite the destabilization caused by this interaction, the overlap of the oxygen $\mathrm{p}$ orbital with a non-bonding electron pair parallel to $\sigma^{*}{ }_{\mathrm{C}-\mathrm{COOH}}$ allowed for additional stabilization of the transition state through the secondary interaction of these orbitals.
On the other hand, in TS1_3,5-out, the hydrogen is on the anti position, forming a dihedral angle of around $180.0^{\circ}$ with the oxygen dipole. This allowed for a $\sigma_{\mathrm{C}-\mathrm{H}} \rightarrow \pi^{*}{ }_{\mathrm{C}=\mathrm{C}}$ interaction, responsible for an increase in the electron density of the alkene and consequently an increase in the HOMO energy of the dipolarophile. In fact, when the orbital energies of the dipolarophile are compared, TS1_3,5-anti always shows a lower HOMO energy. Furthermore, in this transition state, the natural charges over carbons of the double bond are higher, while the natural charge over the carbon atom attached to the $-\mathrm{COOH}$ group is more negative. Therefore, we would expect a lower HOMO for TS1_3,5-anti than for TS1_3,5-out-HB HOMO in addition to more negative charges over the double bond carbons. However, this is not observed. One possible explanation could be the cyclical behavior of charge transfer in the transition state due to the geometry imposed by hydrogen bonding, as hydrogen bonding is responsible for an increase in negative charge on dipole oxygen. This stabilizes the $\sigma^{*}{ }_{\mathrm{C}-\mathrm{H}}$ orbital through electron donation from the p orbital, parallel to the $\mathrm{C}-\mathrm{H}$ bond, which explains the increase in negative charge in the carbon atom $(-0.535)$. The $\sigma$ orbital of the $\mathrm{C}-\mathrm{H}$ bond in the anti position could then donate electron density to $\pi^{*}{ }_{\mathrm{C}=\mathrm{C}}$, thereby increasing the electron density in the double bond region. However, the first one is also parallel to $\mathrm{OC}-\mathrm{COH}$ bond, which allowed for stabilization through a $\sigma_{\mathrm{C}-\mathrm{H}} \rightarrow \sigma^{*}{ }_{\mathrm{C}-\mathrm{OH}}$ interaction and explained the charge over the carbonyl carbon, which is less

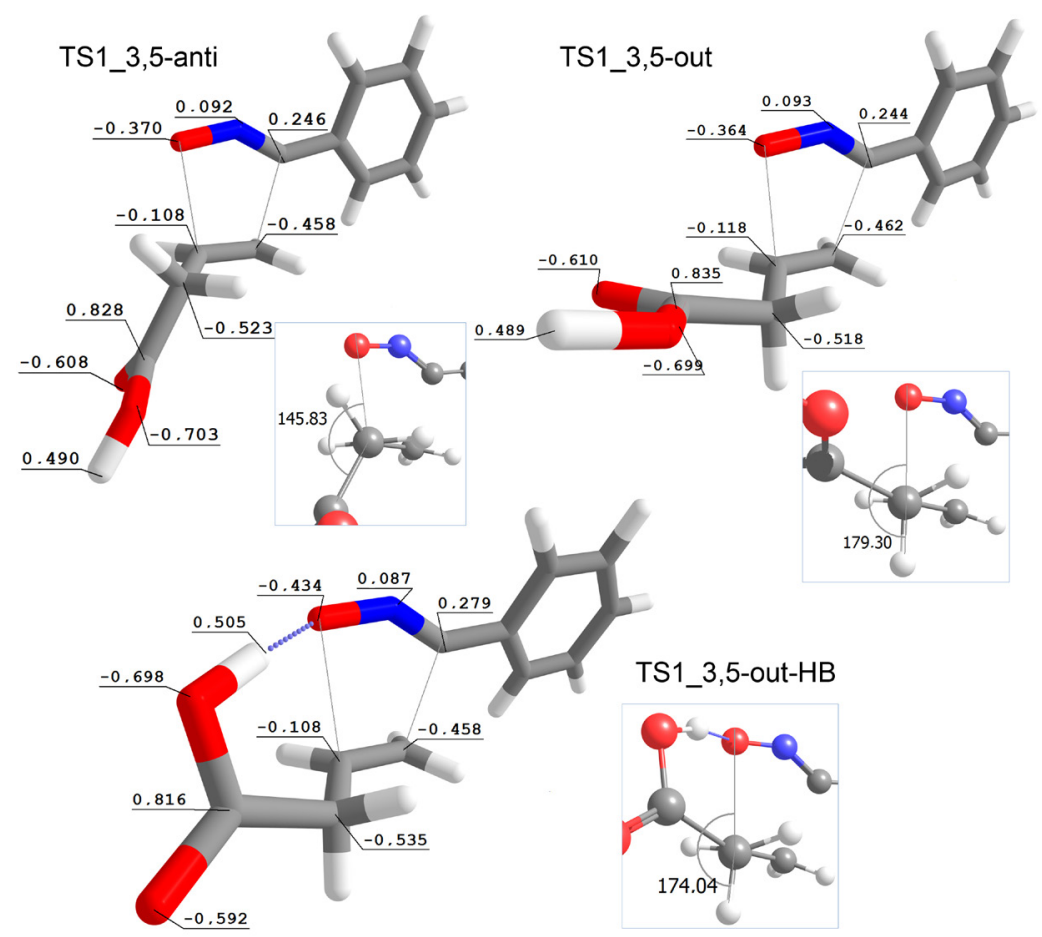

Figure 6. Natural atomic charges obtained for the TS1 calculated at B3LYP/6-311+G(2d,p) level of theory, in the gas phase.Dihedral angles between the oxygen of 1,3-dipole and the group at anti position are highlighted. 
positive in this transition state than in the others. Thus, the alkene substituent group shows an electron withdrawing effect in TS1_3,5-out-HB, producing a low energy HOMO and LUMO molecular orbitals.

The inclusion of the solvent effect may cause a slight decrease in the HOMO and LUMO energies of the dipolarophile. The transition state with a $-\mathrm{COOH}$ group in the anti position is favored in the gas phase because of electrostatic interactions despite the $\pi_{\mathrm{C}=\mathrm{C}} \rightarrow \sigma^{*}{ }_{\mathrm{C}-\mathrm{COOH}}$ destabilizing interactions. The charge separation on the molecule is less pronounced due to the interaction with the solvent reaction field, promoting the transition state stabilized by hydrogen bonding.

\section{Conclusions}

13DC reactions between $\mathrm{BNO}$ and vinylacetic acid were studied by DFT, using the PBE1PBE, B3LYP and CAM-B3LYP functionals. In order to compare the energetic barriers given by DFT calculations, CCSD(T)/6-311+G(2d,p)//B3LYP/6-311+G(2d,p) was carried out to study the first cycloaddition. The solvent effects were taken into account using the CPCM and PCM models with solvents of different dielectric constants (THF, acetonitrile and formamide).

The 3,4-regioisomer is kinetically and thermodynamically disfavored while three 3,5-rotamers are closer in energy. In the gas phase, the anti rotamer presented the lowest energy for the transition state and product. However, considering solvent effects, the out rotamer is always favored. Thus, the preferential TS1 found was TS1_3,5-out and the most stable product was the TS1_3,5-out rotamer. A second cycloaddition occurs between the LUMO of BNO and the HOMO of the product formed in the first cycloaddition. In this reaction, BNO could interact via both faces of 3,5-isoxazoline, generating cis and trans bicycles. The $\beta$ face attack is favored by a small energy difference in the gas phase while the cis isomer is thermodynamically favored by more than $1.0 \mathrm{kcal} \mathrm{mol}^{-1}$. The $\alpha$ face attack presented a lower activation free energy when solvent effects were included. In terms of electronic energy, again, there is a preference for anti rotamers in the gas phase and out rotamers in the condensed phase. In the second cycloaddition, TS2 and the product with a hydrogen bond presented the highest energies.

PBE1PBE has proved to be the best functional to describe this reaction. The three functionals used in this work showed very similar results for molecular geometry calculations, but for the activation free energies, PBE1PBE presented, on average, energies $3.0 \mathrm{kcal} \mathrm{mol}^{-1}$ lower than B3LYP and CAM-B3LYP. The reaction energies differences are larger. B3LYP presented reaction energies approximately $10 \mathrm{kcal} \mathrm{mol}^{-1}$ higher. PBE1PBE and CAM-B3LYP presented similar reaction energies but the former produced more negative values. When compared to the $\operatorname{CCSD}(\mathrm{T})$ calculations, PBE1PBE showed satisfactory results, but provided activation free energies around $5 \mathrm{kcal} \mathrm{mol}^{-1}$ higher than $\operatorname{CCSD}(\mathrm{T})$ calculations. The reaction free energies obtained for the second cycloaddition using B3LYP are positive and much higher than those obtained with $P B E 1 P B E$ and CAM-B3LYP. From this information, it is apparent that the B3LYP is not the best functional to study this reaction.

The energy barriers and reaction energies obtained using CPCM and PCM are very similar, especially when high dielectric constants are used. Although these values are essentially the same for both methods, the energies obtained by CPCM are slightly more negative than those obtained with PCM. Thus, we can conclude that both methods, PCM and CPCM, provide essentially the same results for the cycloaddition reaction studied, especially when the solvent has a high dielectric constant.

\section{Supplementary Information}

Supplementary information is available free of charge at http://jbcs.sbq.org.br as PDF file.

\section{Acknowledgments}

We are grateful for the financial support and scholarships from the Brazilian agencies Conselho Nacional de Desenvolvimento Científico e Tecnológico ( $\mathrm{CNPq}$ ) and Coordenação de Aperfeiçoamento de Pessoal de Nível Superior (CAPES). Research carried out with the support of Centro Nacional de Supercomputação (CESUP), Universidade Federal do Rio Grande do Sul (UFRGS).

\section{References}

1. Woodward, R. B.; Hoffmann, R.; Angew. Chem., Int. Ed. Engl. 1969, 8, 781 .

2. Houk, K. N.; Sims, J.; Duke, J. R. E.; Strozier, R. W.; George, J. K.; J. Am. Chem. Soc. 1973, 95, 7287.

3. Houk, K. N.; Sims, J.; Watts, C.; Luskus, L. J.; J. Am. Chem. Soc. 1973, 95, 7301.

4. Padwa, A.; Pearson, W. H.; Synthetic Applications of 1,3-Dipolar Cycloaddition Chemistry Toward Heterocycles and Natural Products; Wiley; New York, 2002.

5. Collman, J. P.; Devaraj, N. K.; Chidsey, C. E. D.; Langmuir 2004, 20, 1051.

6. Speers, A. E.; Adam, G. C.; Cravatt, B. F.; J. Am. Chem. Soc. 2003, 125, 4686 . 
7. Krasinski, A.; Radic, Z.; Manetsch, R.; Raushel, J.; Taylor, P.; Sharpless, K. B.; Kolb, H. C.; J. Am. Chem. Soc. 2005, 127, 6686.

8. Zhang, H.-Z.; Wei, J.-J.; Kumar, K. V.; Rasheed, S.; Zhou, C.H.; Med. Chem. Res. 2015 , 24, 182.

9. Chronopoulos, D. D.; Tsakos, M.; Karousis, N.; Kokotos, C.; Tagmatarchis, N.; Mater. Lett. 2014, 15, 343.

10. Holzinger, M.; Vostrowsky, O.; Hirsch, A.; Hennrich, F.; Kappes, M.; Weiss, R.; Jellen, F.; Angew. Chem., Int. Ed. 2001, 40, 4002

11. Quintana, M.; Tapia, J. I.; Prato, M.; Beilstein J. Nanotechnol. 2014, 5, 2328.

12. Reisi-Vanani, A.; Shahrokh, L.; Kokhdan, S. N.; Comput. Theor. Chem. 2015, 1051, 72.

13. Fleming, I.; Molecular Orbitals and Organic Chemical Reactions, Reference Edition; Wiley: Chichester, 2010.

14. Alam, A.; Pal, C.; Goyal, M.; Kundu, M. K.; Kumar, R.; Igbal, M. S.; Dey, S.; Bindu, S.; Sarkar, S.; Pal, U.; Maiti, N. C.; Adhikari, S.; Bandyopadhyay, U.; Bioorg. Med. Chem. 2011, 19, 7365 .

15. Dravyakar, B. R.; Kawade, D. P.; Khedekar, P. B.; Bhusari, K. P.; Indian J. Chem., Sect. B: Org. Chem. Incl. Med. Chem. 2008, 47, 1559.

16. Shah, T.; Desai, V.; J. Serb. Chem. Soc. 2007, 72, 443.

17. Tavares, A.; Vilela, D. G.; Toldo, J.; Gonçalves, P. F. B.; Eccher, J.; Bechtold, I.; Sampaio, A. R.; Viscovini, R. C.; Schneider, P. H.; Merlo, A. A.; Liq. Cryst. 2012, 39, 175; Tavares, A.; Livotto, P. R.; Gonçalves, P. F. B.; Merlo, A. A.; J. Braz. Chem. Soc., 2009, 20, 1742; Rampon, D. S.; Rodembusch, F. S.; Gonçalves, P. F. B.; Lourega, R. V.; Merlo, A. A.; Schneider, P. H.; J. Braz. Chem. Soc., 2010, 21, 2100; Merlo, A. A.; Tavares, A.; Toldo, J. M.; Vilela; G. D.; Bechtold, I. H.; Gonçalves, P. F. B.; Kitney, S. P.; Kelly, S. M.; New J. Chem., 2016, 40, 393.

18. Shimura, H.; Yoshio, M.; Hamasaki, A.; Adv. Mater. 2009, 21 , 1591.

19. Huisgen, R.; J. Org. Chem. 1976, 41, 403.

20. Huisgen, R.; J. Org. Chem. 1968, 33, 2291.

21. Rastelli, A.; J. Org. Chem. 1998, 63, 7425.

22. Marakchi, K.; Kabbaj, O.; Komiha, N.; Jalal, R.; Esseffar, M.; J. Mol. Struct.: THEOCHEM 2003, 620, 271.

23. Zhao, H.; Li, X.; Ran, X.; Zhang, W.; J. Mol. Struct.:THEOCHEM 2004, 683, 201.

24. Vullo, V.; Danks, T. N.; Wagner, G.; Eur. J. Org. Chem. 2004, 9, 2046.

25. Acharjee, N.; Banerji, A.; Prangé, T.; Monatsh. Chem. 2010, $141,1213$.

26. Freindorf, M.; Sexton, T.; Kraka, E.; Cremer, D.; Theor. Chem. Acc. 2014, 133, 1423.

27. Izadyar, A.; Bakavoli, M.; Moeinpour, F.; Davoodnia, A.; Res. Chem. Intermed. 2015, 41, 343.

28. Domingo, L. R.; Emamian, S. R.; Tetrahedron 2014, 70, 1267.
29. Domingo, L.; Aurell, M. J.; Perez, P.; Tetrahedron 2014, 70, 4519.

30. Merlo, A. A.; Reações Pericíclicas: Uma Sinfonia de Moléculas e Elétrons; Editora da UFRGS: Porto Alegre, 2012.

31. Houk, K. N.; J. Am. Chem. Soc. 1972, 94, 8953.

32. Gothelf, K. V.; Jørgensen, A.; Chem. Rev. 1998, 98, 863.

33. Sustmann, R.; Tetrahedron Lett. 1971, 29, 2717.

34. Domingo, L. R.; Chamorro, E.; Perez, P.; Eur. J. Org. Chem. 2009, 3036.

35. Hu, Y.; Houk, K. N.; Tetrahedron 2000, 56, 8239.

36. Benchouk, W.; Mekelleche, S. M.; Silvi, B.; Aurell, M. J.; J. Phys. Org. Chem. 2011, 24, 611.

37. Ess, D. H.; Houk, K. N.; J. Phys. Chem. A 2005, 109, 9542.

38. Ess, D. H.; Houk, K. N.; J. Am. Chem. Soc. 2007, 129, 10646.

39. Ess, D. H.; Houk, K. N.; J. Am. Chem. Soc. 2008, 130, 10187.

40. Simón, L.; Goodman, J. M.; Org. Biomol. Chem. 2011, 9 , 689.

41. Lan, Y.; Zou, L.; Cao, Y.; Houk, K. N.; J. Phys. Chem. A 2011, 115, 13906.

42. Linder, M.; Brinck, T.; Phys. Chem. Chem. Phys. 2013, 15, 5108.

43. Burke, K.; J. Chem. Phys. 2012, 136, 150901.

44. Adamo, C.; Barone, V.; J. Chem. Phys. 1999, 110, 6158.

45. Yanai, T.; Tew, D. P.; Handy, N. C.; Chem. Phys. Lett. 2004, 393, 51.

46. Padwa, A.; 1,3-Dipolar Cycloaddition Chemistry, vol. 2; John Wiley \& Sons: New York, 1984.

47. Mersbergen, D. V.; Wijnen, J. W.; Engberts, J. B. F. N.; J. Org. Chem. 1998, 63, 8801.

48. Rispens, T.; Engberts, J. B. F. N.; J. Phys. Org. Chem. 2005, $18,908$.

49. Domingo, L. R.; Picher, M. T.; Arroyo, P.; Sáez, J. A.; J. Org. Chem. 2006, 71, 9319.

50. Becke, A. D.; J. Chem. Phys. 1993, 98, 5648.

51. Barone, V.; Cossi, M.; J. Phys. Chem. A 1998, 102, 1995.

52. Cossi, M.; Rega, N.; Scalmani, G.; Barone, V.; J. Comput. Chem. 2003, 24, 669.

53. Cancès, E.; Mennucci, B.; Tomasi, J.; J. Chem. Phys. 1997, 107, 3032 .

54. Fukui, K.; Acc. Chem. Res. 1981, 14, 363.

55. Hratchian, H. P.; Schlegel, H. B.; J. Chem. Phys. 2004, 120, 9918.

56. Glendening, E. D.; Reed, A. E.; Carpenter, J. E.; Weinhold, F.; NBO Version 3.1; University of Wisconsin, USA, 1998.

57. Frisch, M. J.; Trucks, G. W.; Schlegel, H. B.; Scuseria, G. E.; Robb, M. A.; Cheeseman, J. R.; Scalmani, G.; Barone, V.; Mennucci, B.; Petersson, G. A.; Nakatsuji, H.; Caricato, M.; Li, X.; Hratchian, H. P.; Izmaylov, A. F.; Bloino, J.; Zheng, G.; Sonnenberg, J. L.; Hada, M.; Ehara, M.; Toyota, K.; Fukuda, R.; Hasegawa, J.; Ishida, M.; Nakajima, T.; Honda, Y.; Kitao, O.; Nakai, H.; Vreven, T.; Montgomery Jr., J. A.; Peralta, J. E.; Ogliaro, F.; Bearpark, M.; Heyd, J. J.; Brothers, E.; Kudin, 
K. N.; Staroverov, V. N.; Keith, T.; Kobayashi, R.; Normand, J.; Raghavachari, K.; Rendell, A.; Burant, J. C.; Iyengar, S. S.; Tomasi, J.; Cossi, M.; Rega, N.; Millam, J. M.; Klene, M.; Knox, J. E.; Cross, J. B.; Bakken, V.; Adamo, C.; Jaramillo, J.; Gomperts, R.; Stratmann, R. E.; Yazyev, O.; Austin, A. J.; Cammi, R.; Pomelli, C.; Ochterski, J. W.; Martin, R. L.; Morokuma, K.; Zakrzewski, V. G.; Voth, G. A.; Salvador, P.; Dannenberg, J. J.; Dapprich, S.; Daniels, A. D.; Farkas, O.; Foresman, J. B.; Ortiz, J. V.; Cioslowski, J.; Fox, D. J.; Gaussian 09, Revision C.01; Gaussian, Inc.: Wallingford, 2010.

58. Salvador, P.; Duran, M.; Fradera, X.; J. Chem. Phys. 2002, 116, 6443.

59. Luft, J. A. R.; Meleson, K.; Houk, K. N.; Org. Lett. 2007, 9 , 555.

60. Brown, F. K.; Raimondi, L.; Wu, Y.-D.; Houk, K. N.; Tetrahedron Lett. 1992, 33, 4405.

61. Silvero, G.; Lucero, M. J.; Winterfeldt, E.; Houk, K. N.; Tetrahedron 1998, 54, 7293.

62. Corsaro, A.; Pistarà, V.; Rescifina, A.; Piperno, A.; Chiacchio, M. A.; Romeo, G.; Tetrahedron 2004, 60, 6443.

63. Ponti, A.; Molteni, G.; J. Org. Chem. 2001, 66, 5252.

64. Abda, H.; Aouadi, K.; Gueyrard, D.; Praly, J.-P.; Msaddek, M.; Lett. Org. Chem. 2012, 9, 96.

65. Raimondi, L.; Wu, Y.-D.; Brown, F. K.; Houk, K. N.; Tetrahedron Lett. 1992, 33, 4409.

66. Houk, K. N.; Moses, S. R.; Wu, Y.-D.; Rondan, N. G.; Jäger, V.; Schohe, R.; Fronczek, F. R.; J. Am. Chem. Soc. 1984, 106, 3880 .

67. Fukuda, S.; Kamimura, A.; Kanemasa, S.; Hori, K.; Tetrahedron 2000, 56, 1635 .

68. Li, Y.; Fanf, D.-C.; Phys. Chem. Chem. Phys. 2014, 16, 15224.

69. Sáez, J. A.; Arnó, M.; Domingo, L. R.; Tetrahedron, 2003, 59, 9167.

70. Stagno d'Alcontres, G.; Gazz. Chim. Ital. 1982, 82, 627.
71. Cheong, P. H.-Y.; Yun, H.; Danishefsky, S. J.; Houk, K. N.; Org. Lett. 2006, 8, 1513.

72. Repasky, M. P.; Jorgensen, W.; Faraday Discuss. 1998, 110, 379.

73. Schoenebeck, F.; Ess, D. H.; Jones, G. O.; Houk, K. N.; J. Am. Chem Soc. 2009, 131, 8121.

74. Ledwith, A.; Parry, D.; J. Chem. Soc. C 1966, 1408.

75. Ess, D. H.; Houk, K. N.; J. Am. Chem. Soc. 2007, 129, 10646.

76. Ess, D. H.; Houk, K. N.; J. Am. Chem. Soc. 2008, 130, 10187.

77. Engels, B.; Christl, M.; Angew. Chem., Int. Ed. 2009, 48, 7968.

78. Carey, F. A.; Sundberg, R. J.; Advanced Organic Chemistry: Structure and Mechanisms, part A, $5^{\text {th }}$ ed.; Springer: New York, 2007.

79. Clayden, J.; Geeves, N.; Warren, S.; Organic Chemistry, $1^{\text {st }}$ ed.; Oxford University Press: Oxford, 2000.

80. Fleming, I.; Frontier Orbitals and Organic Chemical Reactions; John Wiley \& Sons: New York, 1976.

81. Böhm, T.; Weber, A.; Sauer, J.; Tetrahedron 1999, 55, 9535.

82. Kuznetsov, M. L.; Kukushkin, V. Y.; Haukka, M.; Pombeiro, A. J. L.; Inorg. Chim. Acta 2003, 356, 85.

83. Wang, H.; Kohler, P.; Overman, L. E.; Houk, K. N.; J. Am. Chem. Soc. 2012, 134, 16054.

84. Elender, K.; Riebel, P.; Weber, A.; Sauer, J.; Tetrahedron 2000, $56,4261$.

85. Albini, F. M.; Vitali, D.; Oberti, R.; Caramella, P.; J. Chem. Res., Miniprint 1980, 10, 4355; Albini, F. M.; Vitali, D.; Oberti, R.; Caramella, P.; J. Chem. Res., Synop. 1980, 10, 348

86. Stverkova, S.; Zak, Z.; Jonas, J.; Liebigs Ann. Chem. 1993, 1169.

Submitted: September 22, 2015

Published online: January 25, 2016

FAPERGS/CAPES has sponsored the publication of this article. 